\title{
The Development Status of Taiwan Laser Processing Industry
}

\author{
Ching-Long CHIU, Kuang-Po CHANG, and Ji-Bin HORNG \\ Additive Manufacturing and Laser Application Center, ITRI South Region Campus, Industry Technology Research Institute, Taiwan
}

(Received September 30, 2014)

\begin{abstract}
The Taiwan laser industrial supply chain is still establishing. The Laser Valley Project now is the driving force of the industrial development. For helping the semiconductor and micro-electronics industries, the laser processing industry has been grown up in these 10 years. However, it needs more technology and collaboration to strengthen the industry. This paper shows that the development status of Taiwan laser industry. It is tailored to make better understanding of Taiwan laser industry and more collaboration between Taiwan and Japan.
\end{abstract}

Key Words: Taiwan, Laser, Industry

\section{Introduction}

There has been over 30 years for laser application in Taiwan. Most of these applications were science research, medical therapy and small industrial applications. In early times, the whole module and even systems were imported from US, Europe and Japan. As semiconductor industry had been established in Taiwan, laser diode began to be produced for laser pointer at 1996. As market needs increasing, the makers of the laser pointer increased to more than 20 companies at that time. In 1990s, the industrial laser system began to be applied in Taiwan on scriber for semiconductor, laser cutter for sheet metal etc. However, the machine price was affordable only to large companies.

As semiconductor and optoelectronics industry were booming in Taiwan, the imported quantities of laser machines began to increase. Fig. 1 shows Taiwan's import and export value of the laser machine and related modules from 2006 to 2013. From the figure, the import value is 6 times more than export

\section{Taiwan's laser industry import and export statistics}

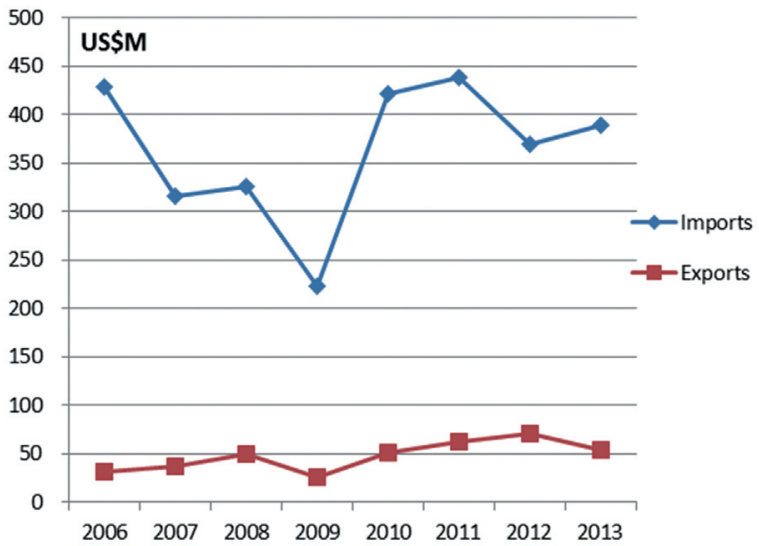

Fig. 1 Taiwan's laser industry import and export statistics (from Taiwan Customs Administration, Ministry of Finance of Taiwan).
Table 1 Ranking of laser machine import value and quantity by country, 2013 .

\begin{tabular}{|c|c|c|c|}
\hline 2013 Laser Import & & Value $\%$ & Quantity \% \\
\hline \multirow[t]{8}{*}{ Laser Process Machine } & Japan & 60.7 & 38.9 \\
\hline & Swiss & 8.3 & 2.0 \\
\hline & Korea & 7.4 & 2.2 \\
\hline & Germany & 7.2 & 9.0 \\
\hline & US & 5.2 & 9.3 \\
\hline & Singpore & 3.5 & 1.8 \\
\hline & China & 3.4 & 33.6 \\
\hline & Others & 4.4 & 3.3 \\
\hline \multirow[t]{7}{*}{ Laser Machine for SEMI } & Japan & 60.3 & 61.6 \\
\hline & Korea & 21.7 & 17.2 \\
\hline & Netherlands & 5.1 & 1.1 \\
\hline & China & 3.0 & 4.9 \\
\hline & Germany & 2.8 & 2.6 \\
\hline & US & 2.5 & 7.4 \\
\hline & Others & 4.7 & 5.2 \\
\hline \multirow[t]{7}{*}{ Laser Welding Machine } & Germany & 68.4 & 22.4 \\
\hline & Japan & 15.5 & 13.1 \\
\hline & China & 8.7 & 48.6 \\
\hline & Korea & 5.0 & 3.7 \\
\hline & US & 1.5 & 6.5 \\
\hline & Italy & 0.4 & 2.8 \\
\hline & Others & 0.5 & 2.8 \\
\hline
\end{tabular}

value. It means that Taiwan's laser application is quite dependent on imports.

Table 1 shows the import value and quantity of laser machines at 2013. From the table, Japan is the main import nation of laser machine especially in laser processing machine and laser machine for semiconductor.

Recently, there are some local companies would like the la- 


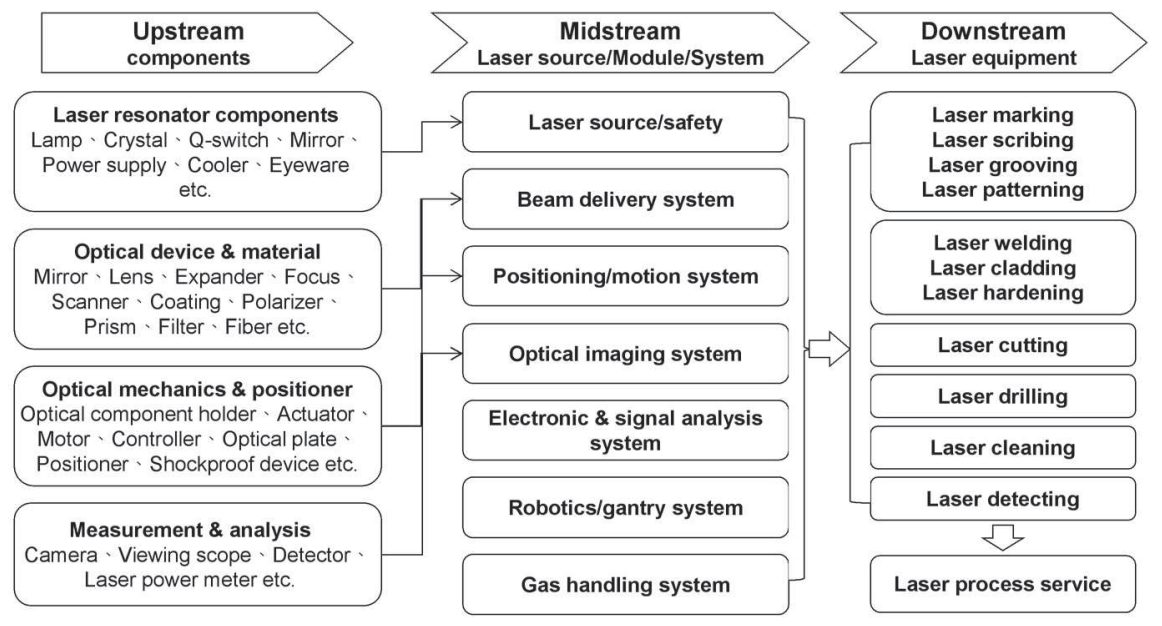

Fig. 2 The laser industry supply chain.

ser industry to be more independent. The applications they would like to develop are semiconductor, FPD, Micro-electronics etc. However, Taiwan's laser industrial supply chain is still dependent on foreign suppliers. Most key components and modules still need to be imported.

\section{The industry status of Taiwan}

Taiwan laser industry supply chain is listed in Fig. 2. The portion of the upstream includes components of laser source, optical parts, optical materials and accessories firms. That of the midstream are for laser source, beam deliver system, motion system, optical imaging system, electronic control system and assisting subsystems. The downstream are of the processing equipment such as marking, cutting, welding, drilling, cleaning, detecting etc. Countries like US, Germany, Japan are all having complete industry chains from upstream to downstream. Unlike that semiconductor, FPD, LED industries being matured in Taiwan, the laser industry is still in downstream of the supply chain.

Most of Taiwan laser companies are in downstream of the supply chain. There was a 10 -year development movement which progressively moves them to midstream. In upstream, there are a few companies producing laser diodes for communication and consumer product. Some companies produce optical holders, actuators and laser grade optical coating.

In midstream, there was no company producing laser source and beam deliver system 3 years ago. Recently, 2 3 companies began to develop nanosecond UV DPSS and picosecond fiber laser for optoelectronics and microelectronics industry by governmental supported projects.

Most midstream optical companies are foreign product agencies of IPG, SPI, Canon, II-VI etc. However, some companies are aiming to develop control subsystem, opto-mechanics-electronic subsystem and motorized positioning system. They have gradually become Taiwan's famous brands. The companies in the downstream section are the laser machine tool makers and foreign agencies. The makers are like Tongtai, UVTech, Soco, E\&R etc. They work with micro etectronics, glass plates, and metal tubes industry. The agencies are of the brands such as TRUMPF, MITSUIBISHI, Amada, EOS etc. The machine tool market share of the Taiwan products is still lower than the foreign ones. However the gap is gradually reduced. There are some companies providing processing services for mentioned application industries. The services include wafer drilling, glass cutting, PCB drilling and marking for metal and plastics. As more technology developed domestically by non-profiting technology research institutes, more companies began to produce laser machine even laser key components for many applications.

\section{The technology innovation of Taiwan}

Taiwan's important laser technology development projects are almost supported by the government. The Laser Valley Project is the largest laser project supported by Department of Industrial Technology (DoIT) of Ministry of Economic Affairs (MOEA). The goal of the project is to build the laser industry cluster in southern Taiwan. It is based on the industry to build and strengthen laser industry supply chain. By integrating key patents, core technologies, researchers of non-profiting research institutes, the Laser Optics Valley is shaped. It is creating spotlights of industry and capable of international competitions. In order to achieve the goal, there are four strategies namely, cultivating technology, leading innovation, entrepreneurship and enhancement of technology and product.

Cultivating technology is to build up the technology basis from non-profiting research institutes. Based on the cultivating technology, the companies could develop new, innovational technology and processing. The strategy for companies which were not in the laser industry but are beginning to build up innovational laser applications is called leading innovation. The strategy for companies which have had laser processing ability and are developing new applications is called enhancement of technology and product. Through the innovation and enhancement, new companies are starting up. The process is called entrepreneurship.

Additive Manufacturing and Laser Application Center (AMLAC) of Industry Technology Research Institute (ITRI) based on the Southern Campus at Liujia, Tainan is the major non-profiting research institute of the Laser Valley Project. The core technologies of AMLAC are fiber laser, ultra-fast and micro/nano laser materials processing, high power laser processing component and laser additive manufacturing. The development of the all-fiber laser is from nano-second fiber laser to nano/pico-second hybrid fiber laser. The laser is suitable for multi-color marking and surface treatment on metal, ceramic etc.

Thanks to nonlinear absorption effect, ultra-fast laser is less prone to varying materials band gaps. The ultrafast laser application group of ITRI is able to drill high-precision $(<1 \mu \mathrm{m})$ high-aspect ratio holes $(>1: 10)$ in virtually any materials. U1- 
Total solution provider for metal AM in Taiwan

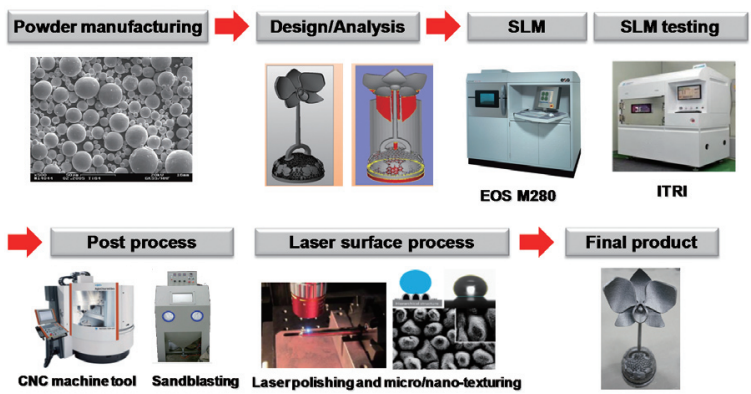

Fig. 3 Total solution provider for metal AM in Taiwan.

trafast machined PLA/PEG medical parts have proved biocompatibility. ${ }^{1)}$ The fs laser polishing has reached $100 \mathrm{~nm}$ RA on metal surface. The unique micro/nano structuring induced by ultrafast laser (LIPSS) has gained quite a few industrial applications. Among them anti-adhesion LIPSS treatment on high precision mold is emerging. ${ }^{2,3)}$ LIPSS hydrophilic/hydrophobic surface has been applied on electrosurgical blade and has proved better tissue recovery. LIPSS treatment of dental implant increases the biocompatibility.

The laser additive manufacturing service process has established at Liujia as shown in Fig. 3. It includes the whole process from powder making to final product. Based on the theoretical study, optical path and process design could be adjusted to optimize the manufacture processing. Fig. 4 has shown the latest product by the AM Lab. of AMLAC. A 3D printed and gold plated titanium hairpin made by the team of AMLAC has won the top prize of the Singapore International Jewelry 3D Printing Competition. The art piece is named the Orchid Spirit which beat 70 rival designs from seven countries. This orchid-shaped hairpin is not only decorative but also functional. It was designed and made in a one-piece construction and which meets all of the demands.

In addition to the making of cultural innovation and jewelry, the laser metal additive manufacturing could also be applied on conformal cooling channel of mold, medical equipment such as dental implant/crown, and bone implant etc.

\section{Conclusion}

The Laser Valley Project which executed from 2011 would

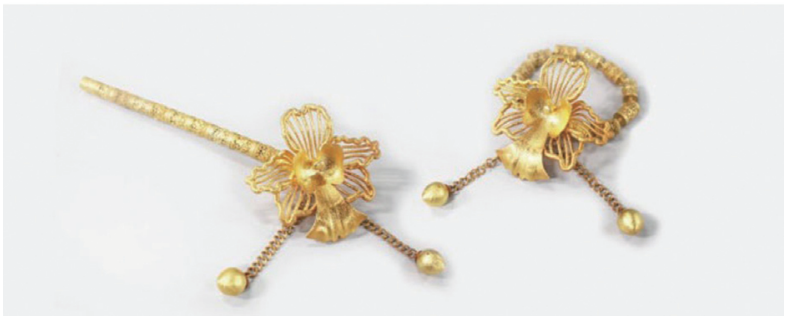

Fig. 4 The "Orchid Spirit" design and manufacture by ITRI.

like to achieve the goal by four strategies and three ways are used such as key component independence, laser innovation applying, industrial posture construction. The results so far, there are 6 new laser companies such as for developing laser source, laser additive manufacturing service, color laser marking service and medical application; 6 application clusters such as for AM, laser source, welding, hand-tool, etc.; 4 research alliances and Taiwan international industry application exhibition. Up until June 2014, there have 800 million TWD investment been promoted; over 200 new employees and over 2 billion TWD derived industrial value by the Laser Valley Project. However, the industrial development not only needs national organization assisting, but also the international collaboration. For the economic development, the laser industry establishment is one means of the industrial upgrading. We hope that there are more collaboration between industrial chain, and more international collaboration to create working jobs and incomes and the Laser valley could boost the economic growth.

\section{References}

1) H. W. Wang, C. W. Li, C. W. Cheng, and G. J. Wang: International Design Engineering Technical Conferences and Computers and Information in Engineering Conference, 2011 (Washington DC, United states, 2011) p. 33.

2) C. Y. Lin, P. H. Wu, K. P. Chang, C. W. Cheng, and S. M. Huang: Journal of Laser Micro Nanoengineering 7 (2012) 54.

3) P. H. Wu, C. W. Cheng, C. P. Chang, T. M. Wu, and J. K. Wang: Journal of Micromechanics and Microengineering 21 (2011).

4) C. Y. Lin, C. W. Cheng, and K. L. Ou: Physics Procedia 39 (2012) 661 